\title{
Postconsolidation Maintenance and Monitoring in Patients With Acute Promyelocytic Leukemia
}

\author{
Chezi Ganzel, MD; Dan Douer, MD; and Martin S. Tallman, MD
}

\begin{abstract}
Acute promyelocytic leukemia (APL) is a unique subtype of acute myeloid leukemia (AML). Its exclusivity is reflected by both the clinical course and the management of patients. This article discusses 2 aspects of the unique management of patients with APL: the role of maintenance therapy and polymerase chain reaction (PCR) monitoring. Despite common practice, the efficacy of maintenance therapy in APL is still debated, and the introduction of arsenic trioxide into frontline protocols makes this debate even more challenging. This article also attempts to clarify details regarding the type and duration of maintenance treatment. The presence of residual leukemic cells, seen using PCR analysis of the PML/RAR $\alpha$ fusion gene product, in patients who have experienced a complete response has been shown to have a high correlation with subsequent relapse. This fact led to the broad use of PCR monitoring techniques in patients with APL. Practicing clinicians face several questions with regard to monitoring, such as what is the best technique for monitoring patients with $\mathrm{APL}$, who can benefit the most from these tests, what are the best time points, and for how long is monitoring recommended. These questions are addressed in this article. (JNCCN 2013;11:1512-1521)
\end{abstract}

\section{Maintenance Therapy in Acute Promyelocytic Leukemia}

The concept of maintenance therapy in acute leukemia has always appealed to investigators contemplating the idea that long-term nonintensive chemotherapy could eradicate residual leukemia cells that may have remained after previous intensive consolidation. Currently, the prevailing consensus is that maintenance therapy is

From the Leukemia Service, Department of Medicine, Memorial Sloan-Kettering Cancer Center, New York, New York.

Submitted April 19, 2013; accepted for publication July 25, 2013. The authors have disclosed that they have no financial interests, arrangements, affiliations, or commercial interests with the manufacturers of any products discussed in this article or their competitors.

Correspondence: Chezi Ganzel, MD, Leukemia Service, Department of Medicine, Memorial Sloan-Kettering Cancer Center, 1275 York Avenue, New York, NY 10065. E-mail: ganzelct@yahoo.com mandatory in patients with acute lymphoblastic leukemia (ALL), whereas those with acute myeloid leukemia (AML) are unlikely to benefit. ${ }^{1}$ The only exception is acute promyelocytic leukemia (APL), which is the only AML subtype for which maintenance therapy is still routinely administered. Nevertheless, the efficacy and necessity of this approach in APL is uncertain because several clinical trials have shown contradictory results. Minimal residual disease (MRD) can be evaluated in patients with APL through polymerase chain reaction (PCR) analysis of the PML/RAR $\alpha$ fusion gene product. In fewer than $2 \%$ of patients with APL, PCR results remain positive after completion of the consolidation course. $^{2,3}$ It can be argued that the rationale for maintenance therapy is valid only in patients with positive PCR results because they have a target for continuation of therapy. Alternatively, the PCR technique has sensitivity limitations, and therefore perhaps even patients with negative PCR results may have a persistent leukemic clone, and maintenance therapy would be able to eradicate this clone.

The risks of maintenance therapy must also be considered. Long duration of treatment with 6-mercaptopurine (6-MP) and methotrexate (MTX) can suppress the bone marrow and expose patients to infections and even secondary malignancies. ${ }^{4}$

\section{Maintenance Therapy Trials Before the All-Trans-Retinoic Acid Era}

The first 2 reports of the efficacy of maintenance therapy in APL were published in the 1980s before the alltrans-retinoic acid (ATRA) era., 5 These small series showed retrospectively that patients who were treated with 6-MP and MTX maintenance therapy experienced longer remission than those who were not treated with maintenance at all. ${ }^{5,6}$ The GIMEMA group was the first 
to prospectively address the question of the efficacy of maintenance in APL. Their LAP 0389 trial was initiated shortly before the availability of ATRA. They compared idarubicin (IDA) alone versus IDA/ arabinosylcytosine (Ara-C) as induction. After $3 \mathrm{cy}$ cles of different chemotherapeutic regimens for consolidation, patients experiencing complete remission (CR) were randomized to either no treatment or maintenance treatment consisting of 6-MP and MTX for 2 years (Table 1). The 7-year disease-free survival (DFS) and overall survival (OS) rates were not statistically different between the maintenance and nonmaintenance groups (43\% vs $38 \%$ and $51 \%$ vs $61 \%$, respectively). ${ }^{?}$

\section{Maintenance Therapy Trials in the ATRA Era}

In the ATRA era, 4 trials $^{8-13}$ examined this question prospectively through comparing 1 or more arms of maintenance therapy versus an observation arm. In another trial, ${ }^{14}$ maintenance therapy was added to the protocol later, and therefore the results of the years with and without maintenance therapy were compared. Of these 5 trials, 3 showed a benefit for maintenance treatment and 2 showed no benefit, and perhaps even a benefit in the observation arm (Table 1).

\section{North American Intergroup Protocol 10129}

The North American Intergroup APL study I0129 included induction followed by a consolidation cycle of either ATRA or daunorubicin (DNR)/Ara-C. ${ }^{8,9}$ Both arms received a second consolidation cycle of DNR and high-dose Ara-C (HiDAC). Patients experiencing $C R$ were randomized to either maintenance with daily ATRA for 1 year or observation. The 5 -year DFS rate was $61 \%$ in the maintenance group and $36 \%$ in the observation group $(P<.0001)$. OS was not determined according to maintenance groups.

\section{European APL93 Trial}

The European APL93 trial compared induction treatment involving ATRA, DNR, and Ara-C given in 2 different schedules. ${ }^{10,11}$ The consolidation cycle involved 2 cycles DNR and Ara-C in different doses: DNR at $60 \mathrm{mg} / \mathrm{m}^{2}$ and Ara-C at $200 \mathrm{mg} / \mathrm{m}^{2}$ in the first cycle, and DNR at $45 \mathrm{mg} / \mathrm{m}^{2}$ and Ara-C at $1 \mathrm{~g} / \mathrm{m}^{2}$ in the second cycle. The 2-year maintenance therapy included 4 arms: ATRA for 15 days every 3 months; 6-MP/MTX; ATRA/6-MP/MTX; and observation. The 10 -year event-free survival rates were $63 \%$, $73 \%, 80 \%$, and $51 \%$, respectively $(P<.001)$. The 10 year $\mathrm{OS}$ rates were significantly better in those who were assigned to maintenance therapy, which includes chemotherapy $(85.2 \%$ vs $79.2 \% ; P=.02)$, but nonsignificant in those who were assigned to ATRA maintenance $(82.7 \%$ vs $79.4 \%$; $P=.44)$.

\section{Australian APML3 Trial}

The Australian APML3 trial showed the high efficacy of the combination of ATRA/IDA. ${ }^{14}$ The trial did not include maintenance therapy in the beginning, but was subsequently amended to have 3 different single-agent maintenance arms: ATRA, 6-MP, and MTX for 2 years. The statistical analysis compared the 2 periods and showed that the 4-year DFS rate was significantly better $(P<.001)$ in the patients who were treated after the amendment (ie, with maintenance; $78.9 \%$ ) compared with those who were treated before the amendment (ie, without maintenance; 46.9\%). Details regarding the different maintenance groups were not reported, probably because of the small number of patients.

In contrast to these studies, 2 other trials ${ }^{12,13}$ showed opposite results (Table 1 ).

\section{AIDA 0493 Trial}

In the AIDA 0493 trial, patients received ATRA/ IDA as induction and 3 cycles of different chemotherapeutic regimens of consolidation. ${ }^{12}$ These regimens included IDA, Ara-C, mitoxantrone (mitox), etoposide, and 6-tioguanine without ATRA. The maintenance was composed of 4 arms of 2 years of treatment: ATRA for 15 days every 3 months; 6-MP/MTX; ATRA/6-MP/MTX; and observation. In the first period after randomization, a significant decrease in DFS was seen in the no-maintenance arm compared with the 3 other arms. As a result, the protocol was amended and, beginning in February 1997, patients experiencing molecular CR were randomized only to the 2 ATRA-containing options (ATRA only and alternating chemotherapy/ATRA). However, with longer follow-up, the initial differences disappeared, and the 12-year DFS probabilities were very similar among the 4 groups $(70.4 \%, 69.0 \%, 67.6 \%$, and $69.1 \%)$. The OS of the no-maintenance arm and the 3 other groups was also similar $(P=.3317$, the numbers were not reported). Adding the patients after the amendment 
Ganzel et al

\section{Table 1 Maintenance Therapy in Acute Promyelocytic Leukemia: A Summary of the Trials That} Compare Maintenance With No Maintenance

\begin{tabular}{|c|c|c|c|c|c|c|}
\hline & Induction & Consolidation & Maintenance & $\mathrm{n}$ & DFS & os \\
\hline \multirow[t]{3}{*}{$\begin{array}{l}\text { GIMEMA } \\
\text { LAP 03897 }\end{array}$} & \multirow{3}{*}{$\begin{array}{l}\text { IDA, } 10 \mathrm{mg} / \mathrm{m}^{2} \\
\text { days } 1-6 \\
\text { vs } \\
\text { IDA, } 10 \mathrm{mg} / \mathrm{m}^{2} \\
\text { days } 1-4+\text { Ara-C, } \\
200 \mathrm{mg} / \mathrm{m}^{2} \text { days } \\
1-7\end{array}$} & $\begin{array}{l}\text { Cycle } 1: \text { IDA, } 5 \mathrm{mg} / \mathrm{m}^{2} \\
\text { days } 1-4+\text { Ara-C, } 1 \mathrm{~g} / \\
\mathrm{m}^{2} \text { days } 1-4\end{array}$ & \multirow[t]{2}{*}{$\begin{array}{l}\text { 6-MP, } 1 \mathrm{mg} / \mathrm{kg} / \mathrm{d}+ \\
\text { MTX, } 0.25 \mathrm{mg} / \mathrm{kg} / \mathrm{wk} \\
\text { for } 2 \mathrm{y}\end{array}$} & \multirow[t]{2}{*}{58} & \multirow[t]{2}{*}{$7-y: 43.0 \%$} & \multirow[t]{2}{*}{$7-y: 51.0 \%$} \\
\hline & & $\begin{array}{l}\text { Cycle 2: mitox, } 10 \mathrm{mg} / \\
\mathrm{m}^{2} \text { days } 1-5+\text { ETOP, } \\
100 \mathrm{mg} / \mathrm{m}^{2} \text { days } 1-5\end{array}$ & & & & \\
\hline & & $\begin{array}{l}\text { Cycle 3: IDA, } 5 \mathrm{mg} / \mathrm{m}^{2} \\
\text { day } 1+\text { Ara-C, } 150 \mathrm{mg} / \\
\mathrm{m}^{2} \text { days } 1-5+6-\mathrm{TG}, 70 \\
\mathrm{mg} / \mathrm{m}^{2} \text { days } 1-5\end{array}$ & No maint & 58 & $\begin{array}{l}7-\mathrm{y}: 38.0 \% \\
(P=N S)\end{array}$ & $\begin{array}{l}7-\mathrm{y}: 61.0 \% \\
(P=N S)\end{array}$ \\
\hline \multirow{5}{*}{$\begin{array}{l}\text { North } \\
\text { American } \\
\text { Intergroup } \\
\text { APL study } \\
10129^{8,9}\end{array}$} & \multirow{5}{*}{$\begin{array}{l}\text { DNR, } 45 \mathrm{mg} / \mathrm{m}^{2} \mathrm{x} \\
3 \mathrm{~d}+\mathrm{Ara}-\mathrm{C}, 100 \\
\mathrm{mg} / \mathrm{m}^{2} \times 7 \mathrm{~d} \\
\text { vs } \\
\text { ATRA, } 45 \mathrm{mg} / \mathrm{m}^{2}\end{array}$} & $\begin{array}{l}1 \text { cycle: DNR, } 45 \mathrm{mg} / \mathrm{m}^{2} \\
\times 3 \mathrm{~d}+\text { Ara-C, } 100 \mathrm{mg} / \\
\mathrm{m}^{2} \times 7 \mathrm{~d}\end{array}$ & \multirow[t]{2}{*}{$\begin{array}{l}\text { Continuous ATRA, } 45 \\
\mathrm{mg} / \mathrm{m}^{2} \text { for } 1 \mathrm{y}\end{array}$} & \multirow[t]{2}{*}{94} & \multirow[t]{2}{*}{$5-y: 61.0 \%$} & \multirow{5}{*}{$\begin{array}{l}\text { No survival } \\
\text { data } \\
\text { according to } \\
\text { maintenance } \\
\text { groups }\end{array}$} \\
\hline & & $\begin{array}{l}2 \text { cycle: DNR, } 45 \mathrm{mg} / \mathrm{m}^{2} \\
\times 2 \mathrm{~d}+\text { Ara-C, } 2 \mathrm{~g} / \mathrm{m}^{2}\end{array}$ & & & & \\
\hline & & $\begin{array}{l}\text { over } 1 \text { hour q12h } \times 4 \mathrm{~d} \\
\text { vs }\end{array}$ & No maint & 105 & $\begin{array}{l}5-y: 36.0 \% \\
(P<.0001)\end{array}$ & \\
\hline & & Cycle 1: ATRA & & & & \\
\hline & & $\begin{array}{l}\text { Cycle 2: DNR, } 45 \mathrm{mg} / \\
\mathrm{m}^{2} \times 2 \mathrm{~d}+\text { Ara-C, } 2 \mathrm{~g} / \\
\mathrm{m}^{2} \text { over } 1 \text { hour } \mathrm{q} 12 \mathrm{~h} \\
\times 4 \mathrm{~d}\end{array}$ & & & & \\
\hline \multirow[t]{7}{*}{$\begin{array}{l}\text { European } \\
\text { APL93 } 3^{10,11}\end{array}$} & \multirow{7}{*}{$\begin{array}{l}\text { ATRA, } 45 \mathrm{mg} / \mathrm{m}^{2} \\
\text { After CR: DNR, } \\
60 \mathrm{mg} / \mathrm{m}^{2} \times 3 \mathrm{~d}+ \\
\text { Ara-C, } 200 \mathrm{mg} / \mathrm{m}^{2} \\
\times 7 \mathrm{~d} \\
\text { vs } \\
\text { ATRA, } 45 \mathrm{mg} / \mathrm{m}^{2} \\
+ \text { DNR, } 60 \mathrm{mg} / \mathrm{m}^{2} \\
\times 3 \mathrm{~d}+\text { Ara-C, } 200 \\
\mathrm{mg} / \mathrm{m}^{2} \times 7 \mathrm{~d}\end{array}$} & \multirow{2}{*}{$\begin{array}{l}\text { Cycle 1: DNR, } 60 \mathrm{mg} / \\
\mathrm{m}^{2} \times 3 \mathrm{~d}+\text { Ara-C, } 200 \\
\mathrm{mg} / \mathrm{m}^{2} \times 7 \mathrm{~d}\end{array}$} & $\begin{array}{l}\text { ATRA, } 45 \mathrm{mg} / \mathrm{m}^{2} \text { for } 15 \\
\mathrm{~d} \text { q3mo for } 2 \mathrm{y}\end{array}$ & 73 & 10-y EFS: $63.0 \%$ & $10-y: 88.0 \%$ \\
\hline & & & \multirow{2}{*}{$\begin{array}{l}\text { Continuous 6-MP, } 90 \\
\mathrm{mg} / \mathrm{m}^{2} / \mathrm{d}+\mathrm{MTX}, 15 \\
\mathrm{mg} / \mathrm{m}^{2} / \mathrm{wk}\end{array}$} & \multirow[t]{2}{*}{72} & \multirow[t]{2}{*}{ 10-y EFS: $73.0 \%$} & \multirow[t]{2}{*}{$10-y: 93.0 \%$} \\
\hline & & \multirow{5}{*}{$\begin{array}{l}\text { Cycle 2: Ara-C, } 1 \mathrm{~g} / \mathrm{m}^{2} \\
\mathrm{q} 12 \mathrm{~h} \times 4 \mathrm{~d}+\mathrm{DNR}, 45 \\
\mathrm{mg} / \mathrm{m}^{2} \times 2 \mathrm{~d}\end{array}$} & & & & \\
\hline & & & ATRA + 6-MP + MTX & 70 & 10-y EFS: $80.0 \%$ & $94.0 \%$ \\
\hline & & & No maint & 74 & 10-y EFS: $63.0 \%$ & $10-y: 88.0 \%$ \\
\hline & & & & & & $\begin{array}{l}10 \text { y of maint } \\
\text { with CT vs } \\
\text { no CT: } 85.2 \% \\
\text { vs } 79.2 \% \\
(P=.02) .\end{array}$ \\
\hline & & & & & & $\begin{array}{l}10 y \text { of } \\
\text { maint with } \\
\text { ATRA vs no } \\
\text { ATRA: } 82.7 \% \\
\text { vs } 79.4 \% \\
(P=.44)\end{array}$ \\
\hline \multirow[t]{2}{*}{$\begin{array}{l}\text { Australian } \\
\text { APML3 }^{14}\end{array}$} & \multirow{2}{*}{$\begin{array}{l}\text { ATRA, } 45 \mathrm{mg} / \mathrm{m}^{2} \\
+ \text { IDA, } 12 \mathrm{mg} / \mathrm{m}^{2} \\
\text { days } 2,4,6, \& 8\end{array}$} & $\begin{array}{l}\text { IDA, } 12 \mathrm{mg} / \mathrm{m}^{2} \text { days } 2, \\
4,6, \& 8\end{array}$ & $\begin{array}{l}\text { Before amend: no } \\
\text { maint }\end{array}$ & 27 & $4-y: 46.9 \%$ & \\
\hline & & $\begin{array}{l}3 \text { cycles of ATRA, } 45 \\
\mathrm{mg} / \mathrm{m}^{2}, \text { for first } 2 \mathrm{wk} \\
\text { in each } 4 \text {-wk cycle }\end{array}$ & $\begin{array}{l}\text { After amend: ATRA, } \\
15 \mathrm{mg} / \mathrm{m}^{2} \times 2 \mathrm{wk} \mathrm{q3} \mathrm{mo} \\
\text { or MTX, } 15 \mathrm{mg} / \mathrm{m}^{2} / \mathrm{wk} \\
\text { or } 6-\mathrm{MP}, 90 \mathrm{mg} / \mathrm{m}^{2} / \mathrm{d} \text {, } \\
\text { for } 2 \mathrm{y}\end{array}$ & 64 & $\begin{array}{l}4-y: 78.9 \% \\
(P<.001)\end{array}$ & \\
\hline \multirow[t]{5}{*}{ AIDA $0493^{12}$} & \multirow{5}{*}{$\begin{array}{l}\text { ATRA, } 25-45 \mathrm{mg} / \\
\mathrm{m}^{2}+1 \mathrm{DA}, 12 \mathrm{mg} / \\
\mathrm{m}^{2} \text { days } 2,4,6 \\
\& 8\end{array}$} & $\begin{array}{l}\text { Cycle 1: Ara-C, } 1 \mathrm{~g} / \mathrm{m}^{2} \\
\mathrm{q} 12 \mathrm{~h} \times 4 \mathrm{~d}+\text { IDA, } 5 \\
\mathrm{mg} / \mathrm{m}^{2} \text { days } 1-4\end{array}$ & $\begin{array}{l}\text { Continuous 6-MP, } 90 \\
\mathrm{mg} / \mathrm{m}^{2} / \mathrm{d}+\mathrm{MTX}, 15 \\
\mathrm{mg} / \mathrm{m}^{2} / \mathrm{wk}\end{array}$ & 78 & $12-y: 70.4 \%$ & \\
\hline & & $\begin{array}{l}\text { Cycle 2: mitox, } 10 \mathrm{mg} / \\
\mathrm{m}^{2}+\text { ETOP, } 100 \mathrm{mg} / \mathrm{m}^{2}\end{array}$ & $\begin{array}{l}\text { ATRA, } 45 \mathrm{mg} / \mathrm{m}^{2} \text { for } \\
15 \mathrm{~d} \text { q3mo }\end{array}$ & $\begin{array}{l}83 \text { (after } \\
\text { amend: 137) }\end{array}$ & $\begin{array}{l}\text { 12-y: } 69.0 \% \\
\text { (after amend: }\end{array}$ & \\
\hline & & & 6-MP + MTX for 3 & & $72.7 \%)$ & \\
\hline & & $\begin{array}{l}\text { Cycle 3: IDA, } 5 \mathrm{mg} / \mathrm{m}^{2} \\
\text { day } 1+\text { Ara-C, } 150 \mathrm{mg} / \\
\mathrm{m}^{2} \text { days } 1-5+6-\mathrm{TG}, 70 \\
\mathrm{mg} / \mathrm{m}^{2} \text { days } 1-5\end{array}$ & $\begin{array}{l}\text { mo, alternate to } \\
\text { ATRA for } 15 \mathrm{~d}\end{array}$ & $\begin{array}{l}83 \text { (after } \\
\text { amend: } 137\end{array}$ & $\begin{array}{l}\text { 12-y: } 67.6 \% \\
\text { (after amend: } \\
73.6 \% ; P=.534 \text { ) }\end{array}$ & \\
\hline & & & No maint & 76 & $12-y: 69.1 \%$ & NA $(P=.331)$ \\
\hline
\end{tabular}

Abbreviations: 6-MP, 6-mercaptopurine; 6-TG, 6-thioguanine; amend, amendment; Ara-C, cytarabine; ATO, arsenic trioxide; ATRA, all-trans-retinoic acid; BHAC, behenoyl Ara-C; CR, complete response, CT, chemotherapy; DFS, disease-free survival; DNR, daunorubicin, EFS, event-free survival; ETOP, etoposide; GO, gemtuzumab ozogamicin; IDA, idarubicin; maint, maintenance; mCR, molecular complete response; mitox, mitoxantrone; MTX, methotrexate; NA, not available; NS, nonsignificant; OS, overall survival; pts, patients. 
Maintenance and Monitoring in APL

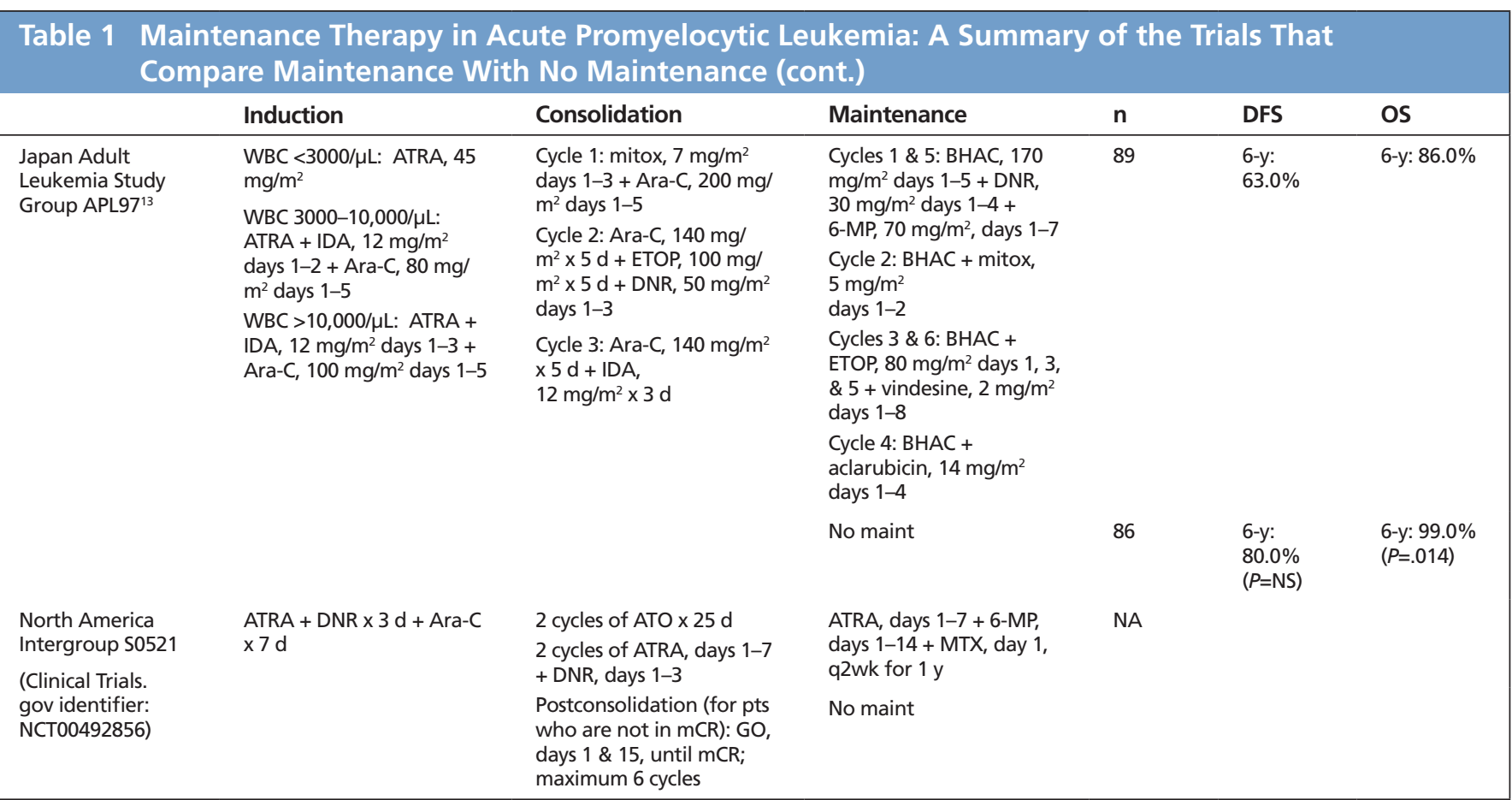

Abbreviations: 6-MP, 6-mercaptopurine; 6-TG, 6-thioguanine; amend, amendment; Ara-C, cytarabine; ATO, arsenic trioxide; ATRA, all-trans-retinoic acid; BHAC, behenoyl Ara-C; CR, complete response, CT, chemotherapy; DFS, disease-free survival; DNR, daunorubicin, EFS, event-free survival; ETOP, etoposide; GO, gemtuzumab ozogamicin; IDA, idarubicin; maint, maintenance; $\mathrm{mCR}$, molecular complete response; mitox, mitoxantrone; MTX, methotrexate; NA, not available; NS, nonsignificant; OS, overall survival; pts, patients.

did not change the results. Comparison of the 2 remaining arms (ATRA-only and alternating chemotherapy/ ATRA) also did not reveal any differences. ${ }^{12}$

\section{Japan Adult Leukemia Study Group APL97 Study}

In the Japan Adult Leukemia Study Group (JALSG) APL97 study, induction therapy involved ATRA with or without IDA and Ara-C, depending on the patient's leukocyte count. Consolidation therapy included 3 different regimens with several combinations of mitox, DNR, etoposide, Ara-C, and IDA. Randomization was between intensified maintenance or none. The maintenance consisted of different combinations of drugs, including behenoyl Ara-C, DNR, 6-MP, etoposide, mitox, vindesine, and aclarubicin. After a median follow-up of 49 months, the predicted 6 -year DFS rate was $63 \%$ in the maintenance group compared with $80 \%$ in the observation group $(P=$ not significant). The OS rate was significantly better $(P=.014)$ in the observation group $(99 \%)$ than in the treated group (86\%). ${ }^{13}$

These 5 trials have several differences, which may explain the different results. In the AIDA 0493 and Japanese trials (the trials that did not find an advantage in maintenance therapy), there was molecular or cytoge- netic confirmation of the diagnosis of APL and of remission, in contrast to the North American and European trials (which found a maintenance advantage), in which the assessment relied only on morphology. It is possible that some of the patients with APL in the American and European trials who were considered to be experiencing $\mathrm{CR}$ and were randomized to maintenance therapy were, in fact, not experiencing molecular CR. In addition, the AIDA 0493 and Japanese trials used IDA and 3 cycles of consolidation, in contrast to the North American and European trials, which used daunorubicin and only 2 cycles of consolidation. The possibility exists that moreintensive consolidation and/or using IDA overcome the advantage of maintenance therapy. ${ }^{12}$ Similarly, the Australian trial included limited initial therapy, which possibly provided a milieu in which maintenance therapy was beneficial.

\section{Maintenance Therapy in the ATO Era}

ATO is considered the most potent anti-APL agent. Its use, which was traditionally reserved for patients experiencing relapse, has expanded and become more a part 
of induction-consolidation therapy. ${ }^{15,16}$ Recently, primary results of the APL 0406 study of the Italian-German Cooperative Groups were presented. ${ }^{17}$ This trial compared the use of ATRA/ATO without chemotherapy versus IDA/ATRA in non-high-risk patients with newly diagnosed APL. After a median follow-up of 31 months, the investigators reported CR rates of $100 \%$ versus $95 \%(P=.12)$, event-free survival rates of $97.0 \%$ versus $86.7 \%(P=.03)$, and OS rates of $98.7 \%$ versus $91.1 \%(P=.03)$. This outstanding response of APL to ATO raises the question of whether all patients who receive ATO as part of their induction-consolidation therapy require maintenance therapy.

What is known about the role of maintenance therapy after ATO treatment? In the C9710 trial, the North American Leukemia Intergroup investigated different maintenance regimens in ATO-treated patients, but did not include an observation arm. ${ }^{18,19}$ In that trial, all patients received 1 cycle of ATRA/ DNR/Ara-C as induction and another 2 cycles of DNR/ATRA as consolidation. The investigational group also received 2 ATO cycles at the beginning of their consolidation. The maintenance groups included 7 days of ATRA every other week for 1 year versus ATRA/6-MP/MTX (Table 2). After a median follow-up of 6.2 years, DFS and OS were not statistically different for the 2 maintenance arms, but only 5 patients who received ATO consolidation experienced relapse, which represents too few events to provide the desired power to detect statistical significant difference. ${ }^{19}$

In the S0521 trial, the North American Leukemia Intergroup investigated the question of whether low- and intermediate-risk patients require maintenance therapy (ClinicalTrials.gov identifier: NCT00492856). The same induction-consolidation therapy was used as in the ATO arm of the C9710 trial protocol, but patients who did not experience $\mathrm{CR}$ were given gemtuzumab ozogamicin. After experiencing CR, patients were randomized to 2 arms of ATRA/6-MP/MTX for 1 year versus observation only (Table 1). The results of this study have not yet been published.

Another question that arises in the ATO era is whether ATO is effective as maintenance therapy. No study has compared ATO versus ATRA or chemotherapy as maintenance therapy, or observation only. A group from Hong Kong examined different ATO maintenance protocols. In their trial, patients received induction with ATRA/DNR/Ara-C and, if they were younger than 65 years, 2 more cycles of DNR/Ara-C

\section{Table 2 Maintenance Therapy in Acute Promyelocytic Leukemia: A Summary of the Trials That} Compare Maintenance Options Without A No-Maintenance Arm

\begin{tabular}{|c|c|c|c|c|c|c|}
\hline & Induction & Consolidation & Maintenance & $\mathbf{n}$ & DFS & os \\
\hline \multirow[t]{4}{*}{ Hong-Kong ${ }^{20}$} & \multirow{4}{*}{$\begin{array}{l}\text { ATRA, } 45 \mathrm{mg} / \mathrm{m}^{2}+ \\
\text { DNR, } 50 \mathrm{mg} / \mathrm{m}^{2} \times 3 \mathrm{~d}+ \\
\text { Ara-C, } 100 \mathrm{mg} / \mathrm{m}^{2} \times 7 \mathrm{~d} \\
\text { For pts aged >70 y: } \\
\text { po arsenic, } 10 \mathrm{mg} / \mathrm{d}+ \\
\text { ATRA, } 45 \mathrm{mg} / \mathrm{m}^{2}\end{array}$} & \multirow{4}{*}{$\begin{array}{l}\text { For pts aged }<65 \\
\mathrm{y}, 2 \text { cycles of: } \\
\text { DNR, } 50 \mathrm{mg} / \mathrm{m}^{2} \mathrm{x} \\
2 \mathrm{~d}+\text { Ara-C, } 100 \\
\mathrm{mg} / \mathrm{m}^{2} \times 5 \mathrm{~d}\end{array}$} & $\begin{array}{l}\text { Oral ATO, } 10 \\
\mathrm{mg} / \mathrm{d}\end{array}$ & 20 & $3-y: 85 \%$ & \\
\hline & & & Oral ATO + & 19 & $3-y: 84 \%$ & \\
\hline & & & ATRA, $45 \mathrm{mg} / \mathrm{m}^{2}$ & & & \\
\hline & & & $\begin{array}{l}\text { Oral ATO + ATRA } \\
+ \text { ascorbic acid, } \\
1 \mathrm{~g} / \mathrm{d}\end{array}$ & 37 & $\begin{array}{l}3-\mathrm{y}: 94 \% \\
(P=\mathrm{NS})\end{array}$ & \\
\hline \multirow{5}{*}{$\begin{array}{l}\text { North } \\
\text { America } \\
\text { Intergroup } \\
\text { C } 9710^{18,19}\end{array}$} & \multirow{5}{*}{$\begin{array}{l}\text { ATRA, } 45 \mathrm{mg} / \mathrm{m}^{2} \\
\text { After CR: DNR, } 50 \mathrm{mg} / \\
\mathrm{m}^{2} \text { days } 3-6+\text { Ara-C, } \\
200 \mathrm{mg} / \mathrm{m}^{2} \text { days } 3-9\end{array}$} & $\begin{array}{l}2 \text { cycles of ATO, } \\
0.15 \mathrm{mg} / \mathrm{kg} / \mathrm{d} \mathrm{x} \\
25 \mathrm{~d}\end{array}$ & ATRA, $45 \mathrm{mg} / \mathrm{m}^{2}$ & 166 & 6-y: NS & $6-y:$ NS \\
\hline & & $\begin{array}{l}2 \text { cycles of ATRA, } \\
45 \mathrm{mg} / \mathrm{m}^{2} \text { days } \\
1-7+\text { DNR, } 50\end{array}$ & & & & \\
\hline & & & \multirow{3}{*}{$\begin{array}{l}\text { ATRA, } 45 \mathrm{mg} / \mathrm{m}^{2} \\
+6-\mathrm{MP}, 60 \mathrm{mg} / \\
\mathrm{m}^{2}+\mathrm{MTX}, 20 \\
\mathrm{mg} / \mathrm{m}^{2} / \mathrm{wk} \text { for } 1 \mathrm{y}\end{array}$} & \multirow[t]{3}{*}{161} & \multirow[t]{3}{*}{ 6-y: NS } & \multirow[t]{3}{*}{ 6-y: NS } \\
\hline & & vs & & & & \\
\hline & & $\begin{array}{l}2 \text { cycles of ATRA, } \\
45 \mathrm{mg} / \mathrm{m}^{2} \text { days } \\
1-7+\text { DNR, } 50 \\
\mathrm{mg} / \mathrm{m}^{2} \text { days } 1-3\end{array}$ & & & & \\
\hline
\end{tabular}

Abbreviations: Ara-C, cytarabine; ATO, arsenic trioxide; ATRA, all-trans-retinoic acid; CR, complete response; CT, chemotherapy; DFS, disease-free survival; DNR, daunorubicin; maint, maintenance; 6-MP, 6-mercaptopurine; MTX, methotrexate; NS, nonsignificant; OS, overall survival; pts, patients. 
as consolidation. Maintenance included 3 arms, each including oral ATO: ATO alone; ATO/ATRA; and ATO/ATRA/ascorbic acid. No observational arm was included (Table 2). The 3-year DFS rate was not significantly different among the 3 arms $(85 \%, 84 \%$, and $94 \%$, respectively), but the numbers of patients on each were too small for the results to be conclusive. ${ }^{20}$

\section{Maintenance Therapy According to Risk Group}

It is well established that patients with APL can be divided into low- and high-risk groups according to their initial WBC count. The common definition for high-risk is a WBC count greater than $10,000 / \mu \mathrm{L} .{ }^{21}$ A retrospective analysis of the APL93 trial found that patients with a WBC count greater than $5000 / \mu \mathrm{L}$ had particularly benefited from maintenance therapy. ${ }^{11}$ Currently, clinical trials in APL are mostly designed with a risk-adapted approach. In these trials, the induction and/or consolidation part of the protocol apply risk stratification of the patient. In contrast, it does not appear that any study has prospectively examined the maintenance question according to risk stratification; this remains to be explored in future APL trials. An example of this approach is the phase II trial conducted by Memorial Sloan-Kettering Cancer Center, in which only high-risk patients receive 2 years of ATRA/ATO maintenance therapy (ClinicalTrials.gov identifier: NCT01404949).

\section{The Optimal Maintenance Regimen and Duration}

Whether maintenance therapy is indicated in patients with APL is unclear. It is even more questionable in low-risk patients who received ATRA and chemotherapy as part of their inductionconsolidation therapy, and particularly in patients treated with ATO.

In accordance with the literature supporting the use of maintenance therapy, the important question remains regarding which regimen is preferred: chemotherapy alone, ATRA, or the combination.

The existing data are inconsistent. In the North American I0129 trial, maintenance with ATRA alone, the only maintenance regimen that was investigated, improved DFS dramatically. ${ }^{8,9}$ In contrast, in the APL93 trial, maintenance with chemotherapy, either alone or with ATRA, significantly improved OS (10-year survival rate, $85.2 \%$ vs $79.2 \% ; P=.02$ ), but long-term survival was not significantly modified by maintenance with ATRA (10-year survival, $82.7 \%$ vs $79.4 \% ; P=.44) .{ }^{10,11}$ It is reasonable that the benefit of maintenance therapy depends on the regimen that was chosen for the induction and consolidation therapies. Therefore, the NCCN Clinical Practice Guidelines in Oncology (NCCN Guidelines) for AML recommend "to use maintenance therapy in conjunction with treatment protocols in which it has been shown to confer benefit"22 (to view the most recent version of these guidelines, visit NCCN.org). One can also conclude from the clinical trials mentioned earlier that if IDA is used during the induction-consolidation phase, as opposed to DNR, maintenance therapy might have no benefit. Until the data are clarified further, common practice and treatment guidelines recommend the use of maintenance therapy.

The desired duration of maintenance therapy is also unclear. The North American Intergroup study prescribed 1 year of maintenance and noted a statistically significant advantage for this treatment. ${ }^{8,9} \mathrm{In}$ contrast, the European study used 2 years of maintenance therapy and found that the risk of relapse significantly decreased when maintenance treatment was given for more than 1 year (hazard ratio, 0.16; 95\% CI, 0.10-0.28; P<.001) compared with less than 1 year. ${ }^{10,11}$ Practically, the recommendation is to use the maintenance regimen as defined in the protocol-driven regimen that is chosen. Even in protocols that include 2 years of maintenance, shortening duration of therapy might be considered in individual patients if maintenance drugs interact with other drugs or toxicity develops.

\section{Postconsolidation Monitoring}

In addition to considering maintenance after consolidation, long-term monitoring for MRD has been studied particularly in APL. The rationale is the excellent correlation between the presence of MRD and subsequent relapse using the APL-specific PML/ RAR $\alpha$ fusion gene product. This correlation is being studied with other AML genetic markers, such as NPM1, but the correlation with outcome is still too premature to apply this strategy routinely for clinical 
Ganzel et al

purposes. In ALL, MRD is routinely tested in children and limarrokely to be used in adults in the near future. $^{23,24}$

In the early 1990s, several retrospective studies showed that reverse transcriptase-PCR (RT-PCR) analysis of the PML/RAR $\alpha$ fusion gene product can detect residual leukemic cells during hematologic remission in patients with APL. ${ }^{25-28}$ Furthermore, it was shown retrospectively that patients who remain PCR-positive after consolidation therapy ${ }^{29}$ or who transformed from PCR-negative to PCRpositive $^{30}$ almost always experience a relapse. The GIMEMA group was the first to report prospectively about the natural history of molecular relapse. They showed that of 21 patients who converted from PCR-negative to PCR-positive, 20 experienced a hematologic relapse at a median of 3 months from the first PCR-positive result. ${ }^{31}$ Follow-up of patients with APL in molecular CR for the possibility of PCR conversion allows molecular relapse to be detected before it evolves into frank hematologic relapse. It should be emphasized that most of the patients who experience relapse do so despite having negative PCR results at the end of the consolidation. Treatment of patients with APL during molecular relapse without waiting for the development of hematologic relapse has several potential advantages. It might reduce the risks of bleeding caused by coagulopathy, of having hyperleukocytosis, and of developing differentiation syndrome while using ATRA and/or ATO. This early intervention while the patient is in molecular relapse has been shown to improve both relapse-free survival ${ }^{32,33}$ and OS $^{32,34}$ compared with treatment during hematologic relapse. Therefore, a negative postconsolidation PCR result became the main goal of APL treatment, and follow-up with repeated PCR tests became the standard of care in these patients.

\section{RT-PCR, Real-Time Quantitative PCR, and Fluorescence In Situ Hybridization}

Despite being the most common monitoring method, RT-PCR has several limitations. It is prone to contamination, may fail to identify poor-quality samples, and lacks the ability to distinguish between decreasing and increasing levels of leukemia-specific transcripts. Real-time quantitative PCR (RQ-PCR) for detection of PML/RAR $\alpha$ has a significant advan- tage in all of these aspects and tends to be a more sensitive tool. In a prospectively analysis of 6727 serial blood and marrow samples from 406 patients with newly diagnosed APL who were receiving ATRA and anthracycline-based chemotherapy, a British group showed that serial molecular monitoring with RQ-PCR to detect an increasing trend in PML/RAR $\alpha$ transcripts provides the strongest predictor of relapse-free survival in APL. ${ }^{33}$

Fluorescence in situ hybridization (FISH) is being used as a diagnostic test in patients with suspected APL. It has the advantage of being relatively rapid and specific but provides no information about the isoform of PML/RAR $\alpha$, which is required for molecular monitoring of MRD, and might be misleading and appear normal in situations in which PML/RAR $\alpha$ is formed as a result of small insertion events. FISH has been shown to be a reliable MRD target $^{35-37}$ but is probably not as sensitive and specific as PCR. ${ }^{38}$

In conclusion, both the European LeukemiaNet and NCCN Guidelines recommend either RT-PCR or RQ-PCR as the preferred monitoring tool in patients with APL. ${ }^{22,39}$

\section{PML/RAR $\alpha$ Analysis in a Patient Treated With ATO}

The kinetics of leukemia cell clearance after the use of ATO is significantly different from that of ATRAbased therapy. Thus, a group from India tried to explore, prospectively, the most informative time point for measuring MRD after a single-agent ATO treatment. Using a multivariate analysis, they reported that a positive RT-PCR result at the end of a singleagent ATO induction therapy was significantly associated with an increased risk of relapse (relative risk, $4.9 ; P=.034) .{ }^{40}$ Because first-line treatment with ATO/ATRA is likely to become more routinely used, similar studies will clarify the preferred schedule for MRD examination.

\section{Frequency and Duration of MRD Monitoring}

The optimal frequency of PCR testing in patients with APL is unknown, but it should reflect the likelihood of relapse. In low-risk patients (WBC at diagnosis $\leq 10,000 / \mu \mathrm{L}$ ), the risk of relapse is very 
low $(\approx 7 \%),{ }^{21}$ and therefore the advantage of PCR monitoring is questionable. In these cases, it seems reasonable that once negative postconsolidation PCR results are achieved, additional PCR tests are likely not justified. On the other hand, in high-risk patients (WBC at diagnosis $>10,000 / \mu \mathrm{L}$ ), the relapse risk is significantly higher $(\approx 10 \%-20 \%)$, and thus testing should continue beyond establishing postconsolidation molecular remission. The APL European LeukemiaNet guidelines recommend that MRD testing be performed every 3 months. ${ }^{39}$ Sanz et $\mathrm{a}^{41}$ recommend that high-risk patients should be monitored every 1 to 2 months for the first year after consolidation and every 3 months for the next 2 years. The NCCN Guidelines leave the decision to "the discretion of the treating physician to determine the appropriate frequency of monitoring for individual patients"22 (to view the most recent version of these guidelines, visit NCCN.org). According to this recommendation, patients who are high risk, are elderly, had interruptions during the consolidation courses, and are unable to tolerate maintenance therapy should be monitored more frequently. ${ }^{22}$

The duration of PCR monitoring tests should also be determined according to the risk of relapse. Low-risk patients probably do not need monitoring PCR at all. For high-risk patients, in whom the rate of relapse is higher, monitoring should be performed for a long period. The different recommendations for the duration of monitoring with PCR, taken together, are for a 2- to 3-year period. However, late relapses, beyond 3 years, can occur in APL, although these are rare. The European group (APL91 and APL93) and North American Intergroup APL trials that were conducted at the beginning of the ATRA era reported that $12.3 \%$ and $1.0 \%$, respectively, of relapses occurred 4 years or more after achievement of CR. ${ }^{42,43}$ Interestingly, the patients experiencing late relapse in the European trials were not characterized as high risk at diagnosis.

\section{Bone Marrow Versus Peripheral Blood Testing}

Using peripheral blood rather than bone marrow to monitor PML/RAR $\alpha$ MRD with PCR is more convenient for patients and their physicians. The large British study mentioned earlier evaluated pairs of samples of peripheral blood and bone marrow. ${ }^{33}$ The investigators reported that, despite having a high correlation in RQ-PCR results during the early stages of treatment, this was not the case in sequential monitoring of prerelapse samples. In the latter, molecular conversion of bone marrow samples preceded that of peripheral blood in 7 of 12 patients evaluated by a median of 29 days (range, 14-72 days). Bone marrow afforded a median increment in sensitivity of 1.50 logs (range, 0.34-2.15 logs) compared with peripheral blood. ${ }^{33}$ The APL guidelines of the European LeukemiaNet recommend testing the bone marrow for MRD every 3 months for a total of 3 years after completion of consolidation therapy. ${ }^{39}$ A delay of 1 month in the diagnosis of molecular relapse seems to have a negligible clinical impact. Thus, the NCCN Guidelines, taking into consideration the convenience and accuracy of testing, recommend that a postconsolidation test be performed on a bone marrow sample, but that subsequent PCR monitoring can be performed on peripheral blood samples ${ }^{22}$ (to view the most recent version of these guidelines, visit NCCN.org). If PCR positivity is detected, in view of the rapid kinetics, a bone marrow test should be repeated as soon as possible and in no more than 2 to 4 weeks. ${ }^{22,39}$ In the time that the results are pending, using ATRA to prevent the development of frank disease might be considered.

Finally, looking forward, ATO promises to become a primary component of induction therapy in APL and a new standard of care. The outcome from initial therapy with ATO-containing regimens may well reduce the need for prolonged maintenance. MRD monitoring, using the PML/RAR $\alpha$ transcripts, is well established in APL. In that respect, APL serves as a model for other AML subtypes in which the role of molecular genetics as a tool for MRD monitoring is being actively investigated.

\section{References}

1. Baer MR. Is there a role for maintenance therapy in acute myeloid leukaemia? Best Pract Res Clin Haematol 2009;22:517-521.

2. Mandelli F, Diverio D, Avvisati G, et al. Molecular remission in PML/RAR alpha-positive acute promyelocytic leukemia by combined all-trans retinoic acid and idarubicin (AIDA) therapy. Gruppo Italiano-Malattie Ematologiche Maligne dell'Adulto and Associazione Italiana di Ematologia ed Oncologia Pediatrica Cooperative Groups. Blood 1997;90:1014-1021.

3. Breccia M, Diverio D, Noguera NI, et al. Clinico-biological features and outcome of acute promyelocytic leukemia patients with persistent polymerase chain reaction-detectable disease 
after the AIDA front-line induction and consolidation therapy. Haematologica 2004;89:29-33.

4. Schmiegelow K, Al-Modhwahi I, Andersen MK, et al. Methotrexate/6-mercaptopurine maintenance therapy influences the risk of a second malignant neoplasm after childhood acute lymphoblastic leukemia: results from the NOPHO ALL-92 study. Blood 2009; 113:6077-6084.

5. Marty M, Ganem G, Fischer J, et al. [Acute promyelocytic leukemia: retrospective study of 119 patients treated with daunorubicin]. Nouv Rev Fr Hematol 1984;26:371-378.

6. Kantarjian HM, Keating MJ, Walters RS, et al. Role of maintenance chemotherapy in acute promyelocytic leukemia. Cancer 1987;59:1258-1263.

7. Avvisati G, Petti MC, Lo-Coco F, et al. Induction therapy with idarubicin alone significantly influences event-free survival duration in patients with newly diagnosed hypergranular acute promyelocytic leukemia: final results of the GIMEMA randomized study LAP 0389 with 7 years of minimal follow-up. Blood 2002;100:3141-3146.

8. Tallman MS, Andersen JW, Schiffer CA, et al. All-transretinoic acid in acute promyelocytic leukemia. N Engl J Med 1997;337:1021-1028.

9. Tallman MS, Andersen JW, Schiffer CA, et al. All-trans retinoic acid in acute promyelocytic leukemia: long-term outcome and prognostic factor analysis from the North American Intergroup protocol. Blood 2002;100:4298-4302.

10. Fenaux $\mathrm{P}$, Chastang $\mathrm{C}$, Chevret $\mathrm{S}$, et al. A randomized comparison of all transretinoic acid (ATRA) followed by chemotherapy and ATRA plus chemotherapy and the role of maintenance therapy in newly diagnosed acute promyelocytic leukemia. The European APL Group. Blood 1999;94:1192-1200.

11. Ades L, Guerci A, Raffoux E, et al. Very long-term outcome of acute promyelocytic leukemia after treatment with all-trans retinoic acid and chemotherapy: the European APL Group experience. Blood 2010;115:1690-1696.

12. Avvisati G, Lo-Coco F, Paoloni FP, et al. AIDA 0493 protocol for newly diagnosed acute promyelocytic leukemia: very long-term results and role of maintenance. Blood 2011;117:4716-4725.

13. Asou N, Kishimoto Y, Kiyoi H, et al. A randomized study with or without intensified maintenance chemotherapy in patients with acute promyelocytic leukemia who have become negative for PML-RARalpha transcript after consolidation therapy: the Japan Adult Leukemia Study Group (JALSG) APL97 study. Blood 2007;110:59-66.

14. Iland $H$, Bradstock $K$, Seymour J, et al. Results of the APML3 trial incorporating all-trans-retinoic acid and idarubicin in both induction and consolidation as initial therapy for patients with acute promyelocytic leukemia. Haematologica 2012;97:227-234.

15. Estey E, Garcia-Manero G, Ferrajoli A, et al. Use of alltrans retinoic acid plus arsenic trioxide as an alternative to chemotherapy in untreated acute promyelocytic leukemia. Blood 2006;107:3469-3473.

16. Ravandi F, Estey E, Jones D, et al. Effective treatment of acute promyelocytic leukemia with all-trans-retinoic acid, arsenic trioxide, and gemtuzumab ozogamicin. J Clin Oncol 2009;27:504-510.

17. Lo-Coco F, Avvisati G, Orlando SM, et al. ATRA and arsenic trioxide (ATO) versus ATRA and idarubicin (AIDA) for newly diagnosed, non high-risk acute promyelocytic leukemia (APL): results of the phase III, prospective, randomized, Intergroup APL0406 study by the Italian-German Cooperative Groups
Gimema-SAL-AMLSG [abstract]. Presented at the 54th ASH Annual Meeting and Exposition; December 8-11, 2012; Atlanta, Georgia. Abstract 6.

18. Powell BL, Moser B, Stock W, et al. Arsenic trioxide improves event-free and overall survival for adults with acute promyelocytic leukemia: North American Leukemia Intergroup Study C9710. Blood 2010;116:3751-3757.

19. Powell BL, Moser BK, Stock W, et al. Adding mercaptopurine and methotrexate to alternate week ATRA maintenance therapy does not improve the outcome for adults with acute promyelocytic leukemia (APL) in first remission: results from North American Leukemia Intergroup trial C9710 [abstract]. Presented at the 53rd ASH Annual Meeting and Exposition; December 10-13, 2011; San Diego, California. Abstract 258.

20. Au WY, Kumana CR, Lee HK, et al. Oral arsenic trioxidebased maintenance regimens for first complete remission of acute promyelocytic leukemia: a 10-year follow-up study. Blood 2011;118:6535-6543.

21. Sanz MA, Lo Coco F, Martin G, et al. Definition of relapse risk and role of nonanthracycline drugs for consolidation in patients with acute promyelocytic leukemia: a joint study of the PETHEMA and GIMEMA cooperative groups. Blood 2000;96:1247-1253.

22. O'Donnel M, Abbound C, Altman J, et al. NCCN Clinical Practice Guidelines in Oncology: Acute Myeloid Leukemia. Version 2, 2013. Available at: NCCN.org. Accessed: March 11, 2013.

23. Gokbuget N, Kneba M, Raff T, et al. Adult patients with acute lymphoblastic leukemia and molecular failure display a poor prognosis and are candidates for stem cell transplantation and targeted therapies. Blood 2012;120:1868-1876.

24. Bruggemann $M$, Raff $T$, Kneba $M$. Has MRD monitoring superseded other prognostic factors in adult ALL? Blood 2012;120:4470-4481.

25. Biondi A, Rambaldi A, Pandolfi PP, et al. Molecular monitoring of the myl/retinoic acid receptor-alpha fusion gene in acute promyelocytic leukemia by polymerase chain reaction. Blood 1992;80:492-497.

26. Chang KS, Lu JF, Wang G, et al. The $\mathrm{t}(15 ; 17)$ breakpoint in acute promyelocytic leukemia cluster within two different sites of the myl gene: targets for the detection of minimal residual disease by the polymerase chain reaction. Blood 1992;79:554-558.

27. Miller WH Jr, Levine K, DeBlasio A, et al. Detection of minimal residual disease in acute promyelocytic leukemia by a reverse transcription polymerase chain reaction assay for the PML/RARalpha fusion mRNA. Blood 1993;82:1689-1694.

28. Diverio D, Pandolfi PP, Biondi A, et al. Absence of reverse transcription-polymerase chain reaction detectable residual disease in patients with acute promyelocytic leukemia in longterm remission. Blood 1993;82:3556-3559.

29. Fukutani $H$, Naoe $T$, Ohno R, et al. Prognostic significance of the RT-PCR assay of PML-RARA transcripts in acute promyelocytic leukemia. The Leukemia Study Group of the Ministry of Health and Welfare (Kouseisho). Leukemia 1995;9:588-593.

30. Korninger L, Knobl P, Laczika K, et al. PML-RAR alpha PCR positivity in the bone marrow of patients with APL precedes haematological relapse by $2-3$ months. Br J Haematol 1994;88:427-431.

31. Diverio D, Rossi V, Avvisati G, et al. Early detection of relapse by prospective reverse transcriptase-polymerase chain reaction analysis of the PML/RARalpha fusion gene in patients with acute promyelocytic leukemia enrolled in the GIMEMA-AIEOP 
multicenter "AIDA" trial. GIMEMA-AIEOP Multicenter "AIDA" trial. Blood 1998;92:784-789.

32. Esteve J, Escoda L, Martin G, et al. Outcome of patients with acute promyelocytic leukemia failing to front-line treatment with all-trans retinoic acid and anthracycline-based chemotherapy (PETHEMA protocols LPA96 and LPA99): benefit of an early intervention. Leukemia 2007;21:446-452.

33. Grimwade D, Jovanovic JV, Hills RK, et al. Prospective minimal residual disease monitoring to predict relapse of acute promyelocytic leukemia and to direct pre-emptive arsenic trioxide therapy. J Clin Oncol 2009;27:3650-3658.

34. Lo Coco F, Diverio D, Avvisati G, et al. Therapy of molecular relapse in acute promyelocytic leukemia. Blood 1999;94:2225 2229.

35. Zhao L, Chang KS, Estey EH, et al. Detection of residual leukemic cells in patients with acute promyelocytic leukemia by the fluorescence in situ hybridization method: potential for predicting relapse. Blood 1995;85:495-499.

36. Mancini M, Nanni M, Cedrone M, et al. Combined cytogenetic, FISH and molecular analysis in acute promyelocytic leukaemia at diagnosis and in complete remission. Br J Haematol 1995;91:878884.

37. Amare PS, Baisane C, Saikia T, et al. Fluorescence in situ hybridization: a highly efficient technique of molecular diagnosis and predication for disease course in patients with myeloid leukemias. Cancer Genet Cytogenet 2001;131:125-134.

38. Polampalli S, Choughule A, Prabhash K, et al. Role of RT-PCR and FISH in diagnosis and monitoring of acute promyelocytic leukemia. Indian J Cancer 2011;48:60-67.

39. Sanz MA, Grimwade D, Tallman MS, et al. Management of acute promyelocytic leukemia: recommendations from an expert panel on behalf of the European LeukemiaNet. Blood 2009;113:18751891.

40. Chendamarai E, Balasubramanian P, George B, et al. Role of minimal residual disease monitoring in acute promyelocytic leukemia treated with arsenic trioxide in frontline therapy. Blood 2012;119:3413-3419.

41. Sanz MA, Tallman MS, Lo-Coco F. Tricks of the trade for the appropriate management of newly diagnosed acute promyelocytic leukemia. Blood 2005;105:3019-3025.

42. Kelaidi C, Ades L, Chevret S, et al. Late first relapses in APL treated with all-trans-retinoic acid- and anthracycline- based chemotherapy: the European APL group experience (APL 91 and APL 93 trials). Leukemia 2006;20:905-907.

43. Douer D, Zickl LN, Schiffer CA, et al. All-trans retinoic acid and late relapses in acute promyelocytic leukemia: very long-term follow-up of the North American Intergroup Study I0129. Leuk Res 2013;37:795-801. 